\title{
Architectural and town-planning reconstruction problems of the city of Voronezh
}

\author{
Tatyana Mikhaylova ${ }^{1, *}$ Dmitriy Parshin ${ }^{1}$, Vitaly Shoshinov ${ }^{2}$, Anatoliy Trebukhin ${ }^{2}$ \\ ${ }^{1}$ Voronezh State Technical University, Moscow Avenue, 14, Voronezh, 394026, Russia \\ ${ }^{2}$ Moscow State University of Civil Engineering, Yaroslavskoe sh. 26, Moscow, 129337, Russia
}

\begin{abstract}
The analysis of the state of the historically developed urban district of the city of Voronezh is made. The ways of solving the identified architectural and urban problems of reconstruction of historically developed buildings are proposed. The concept of reconstruction of a territory with historical buildings along Vaytsekhovsky Street is presented.
\end{abstract}

\section{Introduction}

At the present time, along with the problem of preserving and restoring historically significant buildings and architectural monuments, the number of which is steadily decreasing not only in Voronezh, but throughout Russia, there is another equally serious problem - the loss of the city's unique architectural appearance.

The situation is complicated every year by a pragmatic approach to building, in which not only new districts but also the historical center is being lined with typical high-rise apartment buildings and office centers characterized by a lack of individuality and destroying the architectural-artistic appearance of streets and the city as a whole despite the fact that the pace of construction now exceeds the needs, both in housing and in office buildings.

\section{Materials and Methods}

To analyze the condition of the historical development of the urban district of Voronezh, a visual inspection of the analyzed territory was carried out, and local experience of new construction, reconstruction and restoration of existing buildings, the documentation regulating the town-planning activity on the territory of the urban district of the city of Voronezh has been studied.

As the main documents and laws that served as the basis for the analysis of the historical development of the urban district of the city of Voronezh, the following documents and laws were used: the town-planning code of the Russian Federation; Federal Law of 17.11.1995 No. 169-FZ "On Architectural Activity in the Russian Federation"; federal law "On objects of cultural heritage (monuments of history and culture) of the peoples of the Russian Federation" of June 25, 2002 N 73-FZ; the resolution of the Government of the Voronezh Region "On the approval of the boundaries of the zones for the protection of objects of cultural heritage of

*Corresponding author: mtvit.1955@mail.ru 
federal significance located on the territory of the urban district of the city of Voronezh, land use regimes and requirements for town planning regulations within the specified zones"; Decision of the Voronezh City Council of December 19, 2008 n 422-ii "On approval of the general plan of the urban district of the city of Voronezh"; Decision of the Voronezh City Council of December 25, 2009, No. 384-ii "On Approval of the Rules of Land Use and Development of the Urban District of the City of Voronezh"; Decision of the Voronezh City Council of 19.06.2008 №190-II "On Approval of the Rules for the Improvement of the Territories of the Urban District of the City of Voronezh", design regulations "Appearance of the facades of buildings and structures in the urban district of the city of Voronezh".

\section{Results}

In the process of analyzing the preserved historical built-up areas of the city of Voronezh, two conditional zones were identified: the central part of the city and its peripheral development on the slopes of the Voronezh reservoir.

When reconstructing existing built-up areas, historically important buildings and monuments of architecture, which status was not included to cultural heritage objects, often fall under demolition. At the same time, for the identified objects of cultural heritage, there is also a danger of being liquidated or modified.

Practically all the heritage buildings, representing historical and architectural value, are on the balance of cities and regions, and attraction of external funds for their maintenance is unlikely due to the peculiarities associated with their operation and economic profitability.

Due to its age, the condition of most historically significant buildings requires immediate major repairs and restoration work. Engineering systems in such buildings are either subject to complete replacement, or simply are absent, and the existing space-planning decision does not meet current requirements [1].

The adaptation of such buildings for commercial use requires re-planning or the construction of additional floors [2]. However, the possibility of such works is limited in connection with the ban on the change of the main load-bearing elements and the external appearance of the building as a whole.

Thus, the objects of cultural heritage do not represent economic value for private investors, since the profit from the construction of new multistory buildings is much greater than from the reconstruction of existing buildings. At the same time, the amount of budget funds to maintain all historical monuments in proper condition is not enough, which leads to their gradual dilapidation and destruction.

The existing provisions in the documents on protection of cultural heritage objects set forth in the Federal Law "On Objects of Cultural Heritage (Monuments of History and Culture) of the Peoples of the Russian Federation" of June 25, 2002 N 73-FZ, are not able to protect historical monuments from unauthorized alteration and liquidation. In particular, the danger to objects of cultural heritage is the allocation of any one part of the building as an object of legal protection, for example, a facade. This approach allows the elimination of the remaining unprotected part of the building, which will lead to a complete loss of its architectural and historical value.

In order to preserve and form the integral architectural-artistic appearance of the city of Voronezh, the requirement of the conformity of the architectural appearance of the new buildings and structures to the project of approved documentation was enshrined in legislation in such documents as: design regulations "Appearance of facades of buildings and structures in the urban district of the city of Voronezh"; Decision of the Voronezh City Council of 19.06.2008 № 190-II "On the approval of the rules for the urban beautification of the territory of the urban district of the city of Voronezh.". Compliance with these requirements should be monitored by representatives of the special monitoring service at all stages of construction. 
In fact, completed projects can significantly differ from the approved sketches, what is excluding the possibility of achieving the stylistic unity of new buildings with existing buildings. One of the examples of the discrepancy between the finished project (Fig. 2) and the approved sketch (Fig. 1) is the residential complex "Heart of the City", located at: Voronezh, Kukolkina street, 11.

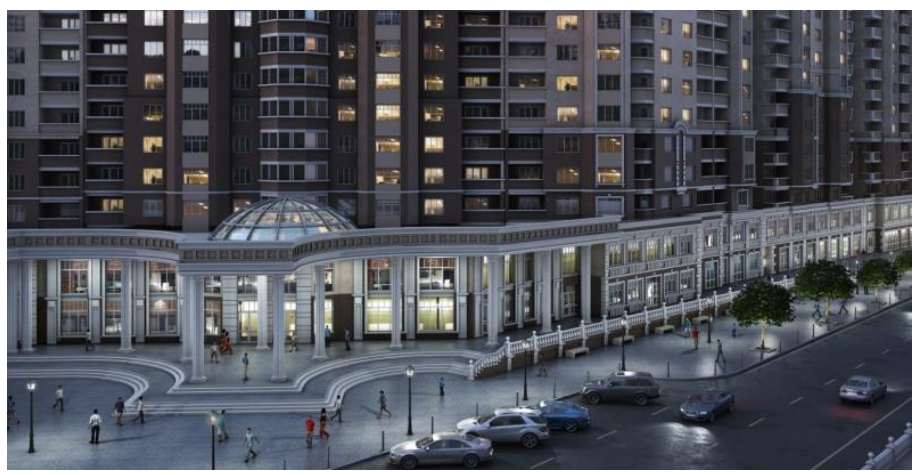

Fig. 1. Approved sketch of the residential complex "Heart of the City".

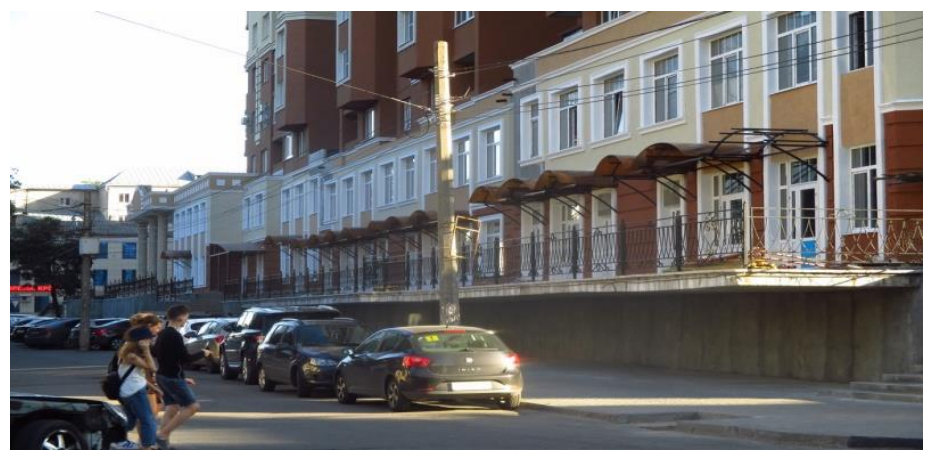

Fig. 2. Actual appearance of the residential complex "Heart of the City".

\section{Discussions}

It should be noted that the main value of the historical center of the city is not only its historical past, but also its architectural heritage [3].

In the conditions of the modern city, the preserved historical buildings are attractive for their color, decorativeness, decoration of facades and best proportions.

That is why the reconstruction of the historical center should assume the formation of a new and modernization of existing environment, repeating the style of architectural monuments.

As measures to create and restore the architectural expressiveness of the city, along with the current decree of the government of the Voronezh region "On the approval of the boundaries of protection zones of cultural heritage sites of federal significance located on the territory of the urban district of the city of Voronezh, land use regimes and requirements for town planning regulations within the boundaries of these zones", a plan with the division of urban area into zones should be developed within which the construction of new and restoration of existing buildings and structures will be implemented in a single architectural style, which will lead to the establishment of a single architectural-artistic appearance of streets and districts. A prerequisite is also to ensure control over the conformity of the external appearance 
of buildings and structures to the established architectural and compositional requirements when approving sketches, as well as at the stages of construction and operation.

To attract private investments for the restoration and exploitation of cultural heritage objects, a system of state and municipal preferences should be used that reduce the amount of rent, taxes or other conditions favorable to private investors in exchange for the restoration of heritage building.

In order to exclude the possibility of dismantling certain elements of cultural heritage objects in the process of exploitation or reconstruction, it is necessary to stop using the term "subject of protection" in the laws fixing the term, in connection with the possible misinterpretation of the present term, permitting the modification or liquidation of other structures not included in the category of protected objects. A necessary decision is also the maintenance of an inventory listing all elements and parts of the cultural heritage object for the purpose of lawful application of penalties to their owners and tenants in case of loss of individual elements of protected objects or uncoordinated changes introduced into their design.

Within the framework of the concept for the reconstruction of a zone with historical buildings developed by a student of the Voronezh State Technical University of the Department of Housing and Communal Services, it is proposed to carry out a complex of reconstructive works along Vaitsekhovsky Street.

According to Appendix No. 2 to the decision of the Voronezh City Council of December 24, 2014 No. 1694-III "Map of functional zones of the urban district of the city of Voronezh," the section of Vaytsekhovsky Street limited by Sacco and Vanzetti, Kaliayev and Tsyurupy streets refers to the zone of construction of three-floored buildings. In this area one- and threefloored stone, wooden residential and administrative buildings are situated (Fig. 3).

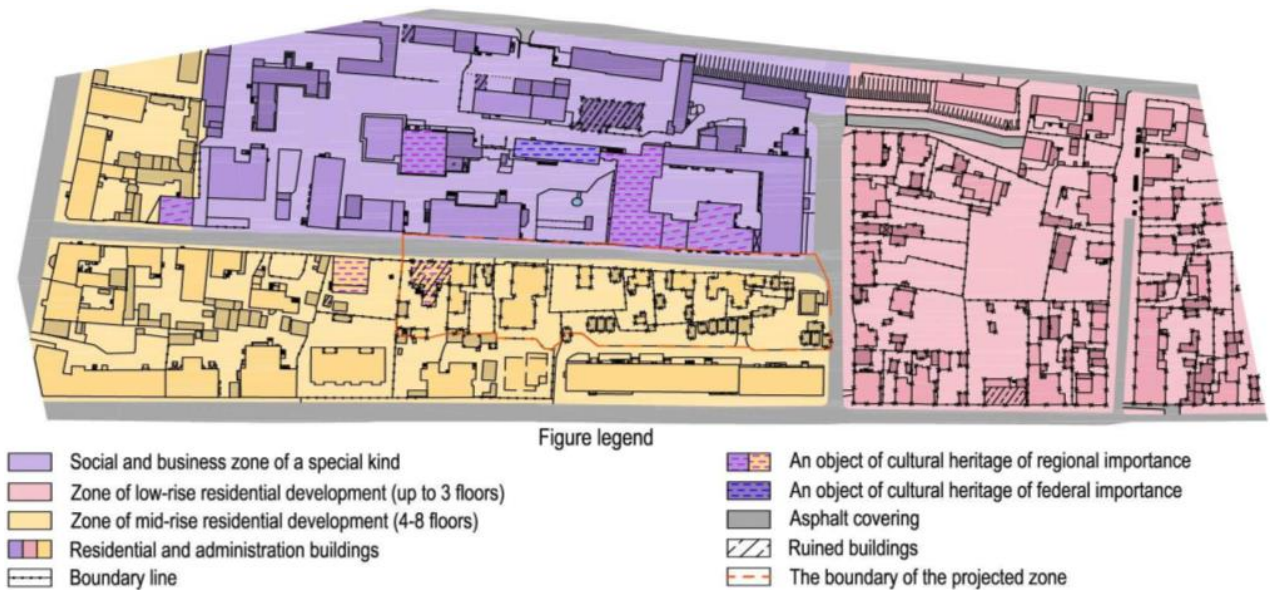

Fig. 3. Scheme of functional zoning of the Vaitsekhovsky street.

In accordance with the list of objects of cultural heritage (monuments of history and culture) of the Voronezh region, 4 cultural heritage sites of regional importance are located on the territory of the street, one of which is the "Tulinov Manor", also known as "Vigel's house", located on the territory in the quarter of the streets of Vaytsehovsky - Kalyaeva - Dostoevskogo. The building was constructed in the 18th century and executed in the Baroque and Empire style, and also includes elements of Gothic architecture (Fig.4); 


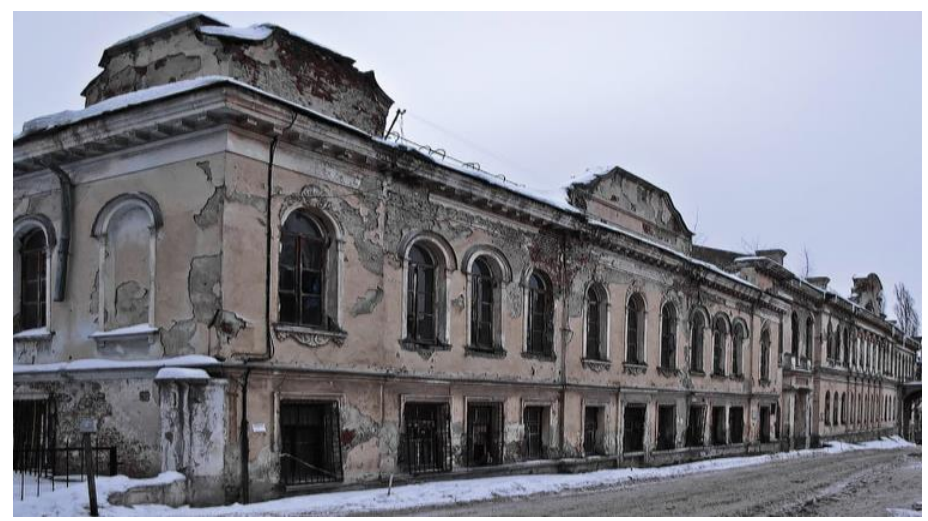

Fig. 4. The current state of the house of Vigel (Tulinov manor).

Vaitsekhovsky Street is of great historical importance, both for the city of Voronezh and for the entire Voronezh region, and its historical and architectural heritage should be restored and preserved for future generations. In this regard, the first stage of the reconstruction of the territory along Vaytsehovskogo Street suggests the restoration of cultural heritage sites, with the restoration of the bearing capacity of structural elements.

In order to create a more comfortable environment and an expressive architectural background, it is proposed to assign the status of the pedestrian zone to Vaitsekhovsky Street. This solution will not only improve the conditions for acquaintance with architectural monuments and for living in the area, but also create a unity of architectural composition of the surrounding buildings and the street space.

At the same time, carrying out only restoration work under the scope of the reconstruction of the considered zone will allow solving architectural issues of cultural heritage objects, however, the issues of renewal of housing stock and landscaping will remain unresolved.

It should be noted that the majority of the housing stock in this zone has a service life of more than half a century, which implies the existence of high indicators of physical and moral deterioration of both the buildings themselves and the utility systems.

The considered site of historical development is characterized by inefficient use of the urban area in view of the predominance of low-rise individual housing and the use of significant areas for individual garages accommodating (Fig. 5).

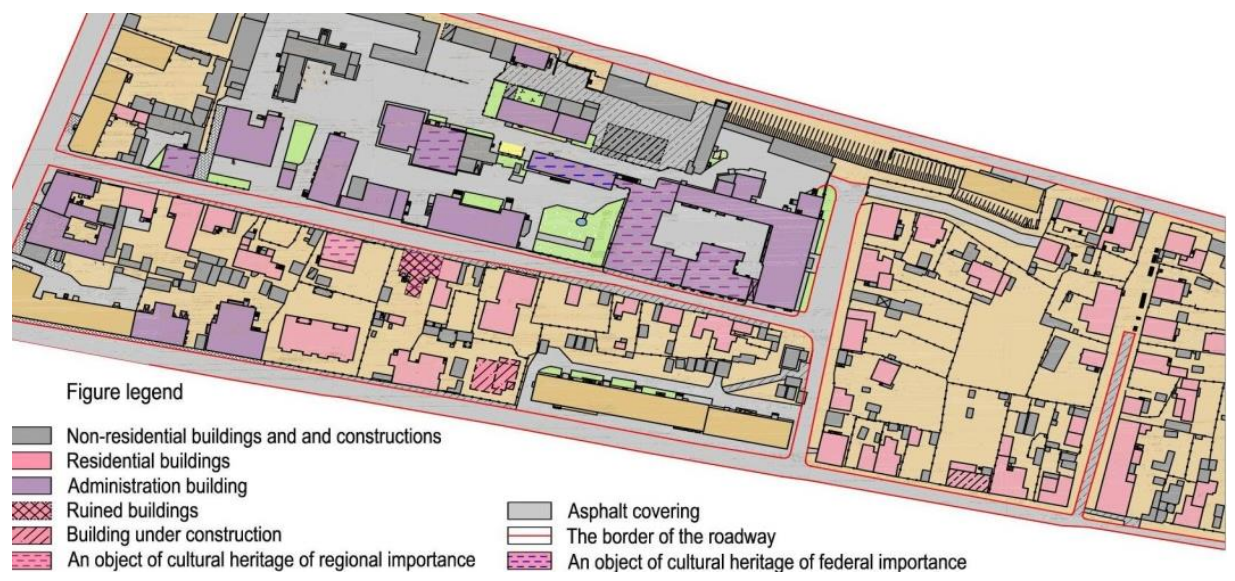

Fig. 5. Scheme of current use of the Vaitsekhovsky street. 
In order to comply with architectural, planning and economic requirements, it is proposed to replace low-rise individual buildings with three-story townhouses [4], taking into account the stylistic features of existing objects of cultural heritage. The variant of the architectural execution of the facades of the townhouse, developed within the framework of the proposed concept for the reconstruction of the territory along Vaitsekhovsky Street, is shown in the Figure 6. This solution will provide additional living space within the boundaries of the reconstructed territory, equalize the total number of storeys of the building and lead to achieving a stylistic unity of the context area with the preserved architectural monuments.
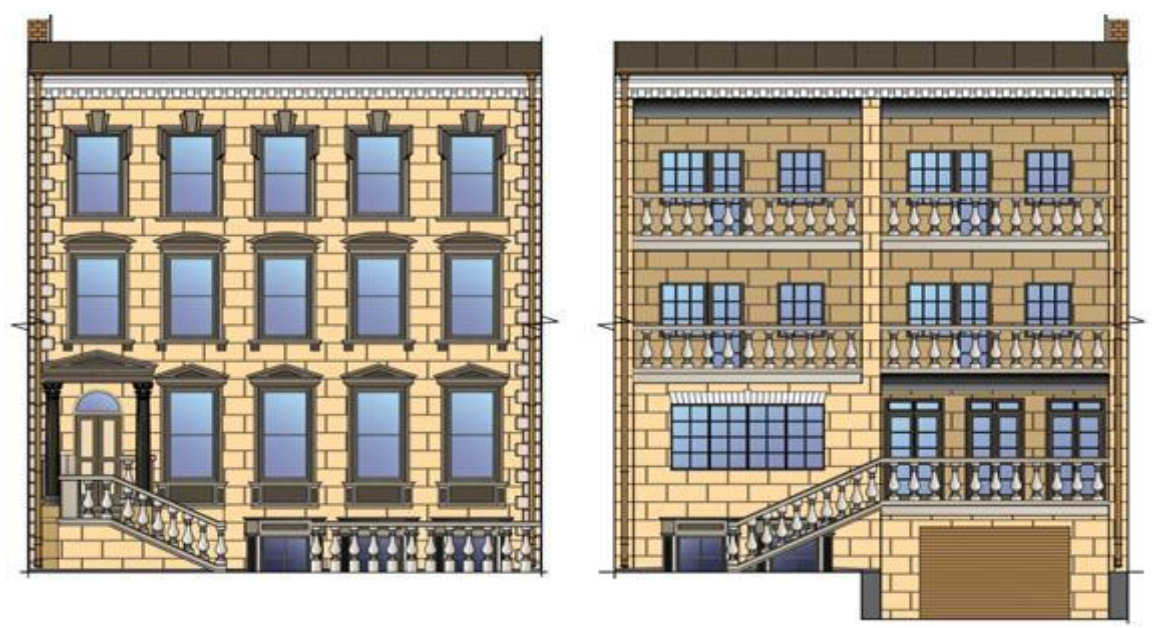

Fig. 6. Street and courtyard facade of the townhouse, developed within the framework of the proposed concept for the reconstruction of the territory along Vaitsekhovsky Street.

It should also be taken into account that the assignment of the pedestrian zone to the Vaitsekhovsky street, the restoration of cultural heritage sites, as well as the renewal and increase of the housing stock as part of its reconstruction will lead to the need to improve transport and pedestrian accessibility, namely: the expansion of the pedestrian zone, the creation of tourist and pedestrian routes and ensuring their connection with the main highways, walking and recreational areas of the city.

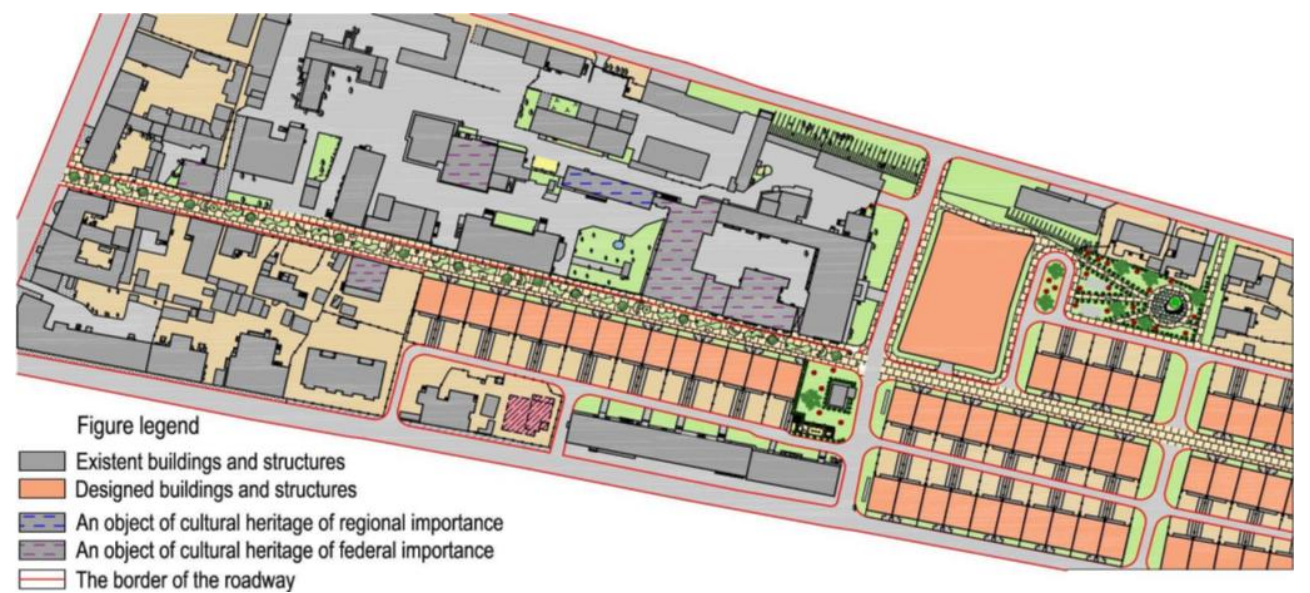

Fig. 7. Project proposal for the scheme of the planning organization of the Vaitsekhovsky street. 
To solve the above problems and improve the overall transport links of the reconstructed territory, it is proposed to connect the streets of Tsyurupa and Dostoevsky by extending the Kalyaev street, as well as extending the Vaitsekhovsky street to the Massalitinov embankment (Fig. 7).

Such a solution will allow the creation of a new tourist route along Vaitsekhovsky Street, connecting the previously proposed tourist routes along Sacco and Vacnetti Street [5], Masalitinov Embankment, and Sevastyanovskiy Descent [6], into a single tourist route "Old Voronezh" on the basis of the Voronezh government decree and development program "Voronezh-tourist", making the city of Voronezh more attractive and historically valuable, both for citizens and tourists visiting the center of the Chernozem region and one of the oldest cities in the center of Russia.

\section{Conclusion}

As a result of the analysis of the historical development of the urban district of the city of Voronezh, it was revealed: 1) the need to improve the regulatory and legal framework governing urban planning; 2) the need to preserve the existing architectural image of the city when developing its reconstruction projects in order to preserve and recreate the artistic and architectural appearance of the city;

The proposed ways of solving the identified architectural and urban problems of reconstruction of historically developed buildings are aimed at creating and restoring the architectural expressiveness of the city, preserving and restoring the cultural heritage of Russian cities;

The proposed concept of reconstruction of the territory with historical buildings along Vaitsekhovsky Street is aimed at renewing the housing stock, creating a comfortable environment for living and acquaintance with architectural monuments, as well as achieving a stylistic unity with the preserved architectural monuments.

\section{References}

1. V. Fedorov, Reconstruction of buildings, structures and urban buildings (INFRA-M, Moscow, 2008)

2. D. Kincaid, Adapting building to changing uses. Guidelines for change of use refurbishment (London, 2002)

3. T. Bradecki, B. Uherek-Bradecka, Advanced Engineering Forum, 12 (2014)

4. I. Chereshnev, Housing construction, 11 (2007)

5. A. Guzeva, Urban planning, infrastructure, communications, 3 (2016)

6. V. Semenov, T. Mikhailova, O. Ermolenko, Urban Development, 5, 33 (2014) 